\title{
Factors influencing general practitioners in the prescription of homeopathic medicines
}

\author{
Russell Abratt \& Julie Lanteigne \\ Graduate School of Business Administration, University of the Witwatersrand, P.O. Box 98, Wits, 2050 South Africa \\ Abratt@zeus.mgmt.wits.ac.za
}

Received June 2000

\begin{abstract}
This study examines the factors influencing general practitioners' prescription behaviour. It differs from previous studies in that the subject is homeopathic medicines and not pharmaceutical drugs. The literature indicates very particular behaviour patterns of doctors' prescription behaviour. The present study provides evidence which contradicts the previous studies. There is thus evidence that what applies to the prescription of ethical pharmaceutical drugs does not apply to the prescription of alternative homeopathic medicines. It follows that marketing practices for alternative medicines should differ from those used by pharmaceutical companies.
\end{abstract}

\section{Introduction}

Trends towards healthier life-styles world-wide and the rising cost of medical treatment, have fuelled the demand for preventative health care. In 1993, a study found that Americans paid more visits to alternative providers than to traditional doctors (Gemigneni, 1997). In 1990, $\$ 13.7$ billion was spent on all categories of unconventional therapies (Eisenberg et al., 1993). The trend toward self-medication that was increasingly evident in the developed countries showed that there was a preference for natural therapy such as homeopathy (Lin \& Dwyer, 1995).

The objective of this study was to review all the possible factors that could influence general practitioners in prescribing homeopathic medicines. General practitioners are the principal targets of the drug industry because they write $80 \%$ of all prescriptions (Stern, 1994).

\section{Homeopathic industry}

Homeopathy is a system of therapeutics based on 'simili' principles, or the law of similars. While conventional medicines, known as allopathic medicine, treats a disease by inducing a condition opposite to the cause of the disease, homeopathic medicines treat by inducing a similar product which produces symptoms similar to those of the disease in order to trigger the body's own defence or immune system (Smith, 1996).

In 1991, the American Congress created the Office of Alternative Medicine (OAM) under the auspices of the National Institute of Health. In January 1997, Washington implemented the nation's broadest alternative therapy law, requiring all indemnity and managed care plans to reimburse 30 categories of providers, including homeopathy (Gemigneni, 1997).

A government organisation was created in South Africa, the Complementary Medicines Committee (CMC), which is a fully instituted committee of the Medicine Control Council (MCC). This committee evaluates all issues regarding complementary medicines for the purpose of recommendations to the MCC. Although the homeopathy industry accounts for approximately $2 \%$ of the total pharmaceutical industry in South
Africa, it is a fast growing industry. Much research has been conducted in the area of pharmaceutical marketing, and more specifically, into factors which influence doctors' prescription habits. (See amongst others Avorn, Chen \& Hartley, 1982; Miller, 1974; Stern, 1994.) No studies have been conducted on the prescribing habits of doctors which apply to homeopathic medicines, mainly because these remedies need not be prescribed by medical doctors in order to be used by patients.

\section{Literature review}

Over the past 30 years researchers have concentrated on organisational buyer behaviour with the objective of expanding marketers' knowledge on how buying decisions are made (Johnson \& Lewin, 1996). Despite this, Stern (1994) argues that the empirical study of buyer behaviour in industrial markets is somewhat neglected. For this reason, clarifying the nature of influences is an area of concem, particularly when considering new products such as alternative medicines. It is reasonable to assert that the homeopathic market exhibits elements of the industrial market: direct contact between manufacturer and practitioner, and the practitioner as retailer (Stern, 1994)

While there has been empirical research on factors influencing medical practitioners' prescription behaviour of ethical drugs, none has addressed homeopathic medicines (Avom, Chen \& Hartley, 1982; Pitt \& Nel, 1988; Stern, 1994 Stolley \& Lasagna, 1969; Walton, 1980; and Watt, 1989). Medical practitioners have a rather unique and multiple role in the buying decision process of medicines. They can be simultaneously users, influencers, gatekeepers and deciders, while patients perform the roles of buyers and users. The general practitioner, by prescribing, actually chooses the product that will be bought, it is he/she that makes the decision.

It is therefore hardly surprising that the bulk of marketing efforts of pharmaceutical manufacturers is directed at medical practitioners (O'Reilly, 1991).

Research shows that there are two general areas of endeavour that influence medical practitioners' prescribing habits. The first are marketing factors and the second professional factors. Marketing factors include sales representatives, 
advertising, the price of the product to the patient, trade shows and symposia. Professional factors of influence include journals, prior experience and education, opinion leaders' influence, recommendations by colleagues and demands by patients. In South Africa $85 \%$ of companies' marketing expenditure involves the salesforce (Gordon, 1982). Medical practitioners rate salespersons as very important sources of information (Lagace, Dahlstrom \& Gassenheimer, 1991 ; Miller, 1974; Pitt \& Nel, 1988).

In the context of practitioners' prescribing decisions, the evidence demonstrates that consumer advertising has a minimal influence (Avorn, Chen \& Hartley, 1982). However, there is evidence that exposure to medical advertising is linked to positive prescribing (Petroshius, Titus \& Hatch, 1995; Pitt \& Nel, 1988; Walton, 1980).

As far as price is concerned, Stem (1994) asserts that because doctors do not pay for the prescriptions, they are largely indifferent to the price charged, and therefore are not influenced by price when prescribing. This finding is supported by Pitt \& Nel (1988) who found that only $15.2 \%$ of physicians believe that the price of the drug is a factor that could influence them in their choice of prescription.

Trade shows and symposia are mainly utilised to introduce new products to the market (Bello \& Lothia, 1993). According to a study conducted by the Health Care Convention and Exhibitors Association, prescriptions of products exhibited increased by $18 \%$ from doctors who participated in an exhibition compared with $2 \%$ from those that did not (Corcoran \& Sullivan, 1996). Medical practitioners regard conferences, lectures and seminars as being more influential than both advertising and sales promotional material (Pitt \& Nel, 1988).

Scientific journals are regarded by medical practitioners as being one of the most influential sources of information regarding their prescription behaviour (Avorn, Chen \& Hartley, 1982; Friedman, 1991). According to Avorn, Chen \& Hartley (1982), the main source of influence is the medical practitioners' own training and experience. This finding is supported by the Pitt \& Nel (1988) and Walt (1989) studies who also concluded that prior experience with a product is the most dominant influence. Recommendations by colleagues in informal discussions was found to be a very important influence factor (Avorn, Chen \& Hartley, 1982; Pitt \& Nel, 1988; Friedman, 1991).

In an environment where there is increasing competition for patients, Check (1983) discusses the possibility that patients who are aware of advertising might 'doctor-shop' until they find a physician who will prescribe what they demanded. In a study conducted by Alperstein \& Peyrot (1993) $79 \%$ of the consumers surveyed believed that requests to their physician for a particular drug would not be a problem.

\section{Propositions}

As a result of this literature review, the following propositions are posited. enced by professional factors than marketing factors.

P2: Sales representatives are the most influential of the marketing factors.

P3: Price has the least influence of all the marketing and professional factors.
P4: Prior experience is the most influential factor of all the professional and marketing factors

P5: The more years of practice a private general practitioner has, the less he/she is influenced by marketing factors.

P6: Private general practitioners with fewer years of practice prescribe more homeopathic medicines than their colleagues with more years experience.

\section{Research methodology}

After an extensive review of the literature, a pilot study was conducted to gain further insights towards preparation of an adequate questionnaire, as well as to uncover relevant issues for the study. The main study involved sending questionnaires to private general practitioners in South Africa.

\section{Pilot study}

This study took the form of personal interviews involving open-ended questions of three private general practitioners who are knowledgeable in homeopathy. This pilot study was undertaken to surface possible issues that may be of relevance to the main study.

The participants noted that general practitioners were conditioned by their education and look suspiciously at anything not learned during their studies. Homeopathy is consequently perceived by the majority of practitioners as non-scientific, similar to a placebo, and thus having no medical effect whatsoever. However, the respondents agreed there is a change of attitude, thanks to new trends in preventative medicine and more natural health care, and to the increased patient awareness of the alternatives to allopathic medicines. The respondents confirmed that all the influences raised in the literature review were relevant. They also confirmed that this study was very important and relevant to all the participants in the health care industry.

\section{Main study \\ Population and sampling}

The population includes the general practitioners in private practice in South Africa. Those working in rural areas were excluded, as they would be more difficult to reach and probably less open to complementary medicines including homeopathy. A random sample of 1000 general practitioners was chosen from a list provided by Med-Pages. Of the 1000 questionnaires mailed to the doctors, 67 were incorrectly addressed, leaving 933 sent to the correct address.

A total of 303 responses were received, but only 278 were useful for analysis. Sixteen questionnaires were discarded because they were completed by specialists and nine questionnaires were discarded because they were incomplete. The response rate was $32.48 \%$ which was regarded as adequate for this exploratory study and for the statistical analysis.

\section{Measuring instrument}

The questionnaire was designed from the literature review and the insights from the pilot study. The questionnaire comprised three sections. Section one was comprised of basic demographic details to be collected from respondents, section two concentrated on the factors that would influence them to prescribe homeopathic medicines. In order to avoid confusion, this section was divided into two parts. In the first 
part, respondents who do prescribe homeopathic medicines were invited to rate the influence of 13 factors on their prescribing behaviour. In the second part, respondents who had never prescribed homeopathic medicines were invited to rate the same 13 factors on how they would influence them to prescribe homeopathic medicines. The scale used was a fivepoint Likert scale. Section three consisted of three openended questions. The first asked the respondents to state their opinion of homeopathic medicines, the second asked why they had never prescribed homeopathic medicines, if that was the case, and the last question asked respondents where they would look for information if they were interested.

The questionnaire was piloted amongst three general practitioners to check for clarity of instructions, ambiguity, and relevance. Minor modifications were made before the questionnaire was distributed

\section{Methods of analysis}

Correspondence analysis was used to re-scale the rating data of the 13 statements from the ordinal to interval level (Bendixen \& Sandler, 1995). The data was then ranked. The average score for the professional factors and the average score for the marketing factors were calculated.

A t-test was then undertaken to ascertain if there is any significance in the variation between the average of the marketing factors and the professional factors. Propositions 1, 2, 3 and 4 were tested according to the rankings of the factors and in comparison with the averages. Proposition 5 was tested with a Chi-square test and proposition 6 was analysed by content analysis and a Chi-square test.

\section{Results}

\section{Profile of respondents}

Out of 278 respondents, 106 were in partnership while 171 were in practice alone. Males accounted for $82.37 \%$ of the sample and 17.63 percent were females. Altogether $62 \%$ of the respondents had more than ten years experience in practice and $28.42 \%$ were in practice for more than 20 years;
$25 \%$ of the respondents were educated at the University of Pretoria and 12\% were educated outside South Africa The rest were educated at other South African medical schools. The majority of respondents, $66.19 \%$, dispensed medicines while 33.81 did not do so. The respondents represented a good cross-section of general practitioners in private practice in South Africa.

\section{Respondents who prescribe homeopathic medicines} Of the 278 respondents, 59 or $21.22 \%$ of the sample prescribed homeopathic medicines. Thus $78.78 \%$ did not do so. A two-sample test was run to verify whether the two groups responded in the same manner to the factors of influence. This is shown in Table 1.

No significant difference was found except when considering the medical education and training, advertisements in consumer magazines, and direct requests from the patient. Those who did not prescribe homeopathic medicines rated their medical education and training as being more influential than those who did prescribe.

Those who did not prescribe homeopathic medicines rated, on average, that advertising in consumer magazines is of moderate influence. On the other hand, those who did prescribe homeopathic medicines rated this factor as being an important influence. As far as direct requests from the patient is concerned, doctors who did not prescribe rated it as being a moderate influence, while those who did prescribe rated this factor as being an important influence.

\section{Rescaling}

The re-scaling of the ratings using correspondence analysis, proved necessary as indicated by the fact that the rescaled values of the Likert scale do not correspond with the nominal values usually assigned to the scale points as illustrated in Table 2.

\section{Ranking the factors of influence}

The factors of influence are shown in Table 3.

Table 1 Equal-variance t-test results $(t-T)$ and the Wilcoxon Rank-Sum test results $(W-T)$ of those who prescribe and those who do not

\begin{tabular}{lccc}
\hline Factors of influence & Do & Do not & P value \\
\hline Cost of the product (W-T) & 2.10 & 2.27 & 0.28 \\
Representatives (W-T) & 1.09 & 1.34 & 0.07 \\
Sales promotional material (W-T) & 0.51 & 0.60 & 0.32 \\
Recommendations by colleagues (W-T) & 2.20 & 2.13 & 0.59 \\
Coverage by medical aid (W-T) & 2.27 & 2.23 & 0.86 \\
Medical leaders (W-T) & 3.01 & 3.20 & 0.21 \\
Articles in medical journals (W-T) & 2.86 & 3.09 & 0.17 \\
Information gained at conferences (W-T) & 2.72 & 2.74 & 0.89 \\
Medical education and training (W-T) & 2.15 & 3.03 & 0.00 \\
Advertisements in medical journals (t-T) & 1.77 & 1.76 & 0.93 \\
Advertisements in consumer magazines (W-T) & 1.82 & 0.86 & 0.02 \\
Prior experience with the product (W-T) & 3.26 & 2.96 & 0.07 \\
Direct requests from the patient (t-T) & 2.61 & 1.44 & 0.00
\end{tabular}


Table 2 Re-scaled values of Likert scale

\begin{tabular}{lcc}
\hline $\begin{array}{l}\text { Scale } \\
\text { point }\end{array}$ & $\begin{array}{c}\text { Nominal } \\
\text { influence }\end{array}$ & $\begin{array}{c}\text { Re-scaled } \\
\text { value }\end{array}$ \\
\hline No influence & 1 & 0.000 \\
Limited influence & 2 & 1.1558 \\
Moderate influence & 3 & 2.0365 \\
Important influence & 4 & 3.0871 \\
Very important influence & 5 & 4.0000 \\
\hline
\end{tabular}

Table 3 Factors of influence ranked in ascending order of influence

\begin{tabular}{lccc}
\hline Factors of influence - all & Mean & Std Dev \\
\hline Sales promotional material & 0.58 & 0.92 \\
Advertisements in consumer magazines & 0.93 & 1.04 \\
Representatives' sales presentations & 1.28 & 1.10 \\
Direct requests from the patients & 1.69 & 1.25 \\
Advertisements in scientific medical journals & 1.76 & 1.13 \\
Recommendations made by colleagues in informal & 2.14 & 1.07 \\
discussions & & \\
Cost of the product to the patient & 2.23 & 1.45 \\
Medical aid cover of the products & 2.24 & 1.35 \\
Information gained at conferences organised by the industry & 273 & 1.16 \\
Medical education and training & 2.84 & 1.23 \\
Prior experience with the product & 3.02 & 1.15 \\
Scholarly articles by specialists in medical journals & 3.04 & 1.03 \\
Recommendations by medical experts, leaders & 3.16 & 1.04 \\
\hline
\end{tabular}

Scale: $0.00=$ no influence; $1.15=$ limited influence; $2.03=$ moderate influence; $3.08=$ important influence; $4.00=$ very important influence

Sales promotion material was the least important factor of influence while recommendations by medical experts was the most important influence factor. Advertisements in consumer magazines had little influence on general practitioners while advertisements in scientific medical journals had some influence on them. Thus, the media decision is an important one for homeopathic marketers because respondents would be influenced by advertisements in scientific medical journals. The findings are divided into professional and marketing factors for further discussion. The ranking of professional factors is shown in Table 4.

The average mean score for the professional factors translated into between 'moderate' to 'important influence'.

Cover of the product by the medical aid, recommendations by colleagues in informal discussions, and direct requests from the patient are the three professional factors that scored below the average mean of the professional factors. Recommendations made by experts, and leaders, rank as the most influential factor of the professional factors. Its score translates slightly more than an 'important influence'.

Table 5 shows the marketing factors of influence.

Overall, the average mean score for the total marketing factors were rated as being of limited influence on the decision to prescribe homeopathic medicines. Sales promotional material, advertisements in both consumer and scientific media as
Table 4 Professional factors of influence

\begin{tabular}{|c|c|c|}
\hline Factors of influence - professional & Mean & Std Dev \\
\hline Direct requests from the patient & 1.69 & 1.25 \\
\hline $\begin{array}{l}\text { Recommendations made by colleagues in informal } \\
\text { discussions }\end{array}$ & 2.14 & 1.07 \\
\hline Cover of the product by the medical aid & 2.24 & 1.35 \\
\hline Average mean of the professional factors & 2.43 & 0.78 \\
\hline Your own medical education and training & 2.84 & 1.23 \\
\hline Prior experience with a product & 3.02 & 1.15 \\
\hline Scholarly articles by specialists in medical journals & 3.04 & 1.03 \\
\hline Medical aid cover of the products & 2.24 & 1.35 \\
\hline $\begin{array}{l}\text { Information gained at conferences organised by the } \\
\text { industry }\end{array}$ & 2.73 & 1.16 \\
\hline Medical education and training & 2.84 & 1.23 \\
\hline Prior experience with the product & 3.02 & 1.15 \\
\hline Scholarly articles by specialists in medical journals & 3.04 & 1.03 \\
\hline Recommendations by experts, leaders & 3.16 & 1.04 \\
\hline Factors of influence - marketing & Mean & Std Dev \\
\hline Sales promotional material & 0.58 & 0.92 \\
\hline Advertising in consumer magazines & 093 & 1.04 \\
\hline Representatives' sales presentations & 1.28 & 1.10 \\
\hline Advertising in medical journals & 1.76 & 1.13 \\
\hline Average mean score of all the factors & 1.81 & 0.72 \\
\hline Cost of the product to the patient & 2.23 & 1.45 \\
\hline $\begin{array}{l}\text { Information gained at conferences organised } \\
\text { by the industry }\end{array}$ & 2.73 & 1.16 \\
\hline
\end{tabular}

well as representatives scored less than the average, showing that they are of limited influence or no influence at all. The most influential marketing factor is information gained at conferences organised by the industry, and this is rated by the respondents as being close to an important influence in their decision to prescribe homeopathic medicines.

\section{Content analysis}

The analysis of the three open-ended questions was subject to content analysis. There were three questions. Firstly, the respondents commented on what their opinions were regarding homeopathic medicines. Secondly, reasons why they had never prescribed homeopathic medicines were given. Thirdly, they responded to the question regarding where they would look for information about homeopathic medicines if they were interested.

\section{Respondents' opinions of homeopathic medicines}

The respondents' comments were divided into 376 statements. These were re-grouped into 14 distinct elements. For clarity, the 14 elements were divided into two different types of statements: the positive statements, and the negative statements.

With regard to the analysis of the positive statements, there were 176 positive statements out of the total of 376 . Hence, $47 \%$ of the statements were positive ones. 
Table 6 Respondents' positive comments about homeopathic medicines

\begin{tabular}{lcc}
\hline Elements of the analysis & Number & Percent \\
\hline 1. Very high opinion of homeopathic medicines & 49 & 28 \\
2. Open to homeopathic medicines & 45 & 26 \\
3. Good in some cases & 39 & 22 \\
4. Good in chronic conditions & 20 & 11 \\
5. Good as an adjunct to allopathic medicines & 17 & 10 \\
6. Increase in patient demand & 4 & 2 \\
7. Affordable & 2 & 1 \\
\hline Total & 176 & 100 \\
\hline
\end{tabular}

Table 6 shows the positive statements made by the respondents.

Some $28 \%$ of the positive statements expressed a very high opinion of homeopathic medicines. Another $26 \%$ expressed openness to homeopathic medicines, and $22 \%$ suggested that homeopathic medicines were appropriate in some cases.

Table 7 shows the negative statements about homeopathic medicines.

Table 7 Respondents' negative comments about homeopathic medicines

\begin{tabular}{lcc}
\hline Elements of the analysis & Number & Percent \\
\hline 1. Homeopathic medicines do not work & 69 & 55 \\
2. Sceptical & 25 & 20 \\
3. Homeopathic medicines are not scientifically proven & 20 & 16 \\
4. Product problems & 8 & 6 \\
5. Too expensive & 3 & 3 \\
\hline Total & 125 & 100 \\
\hline
\end{tabular}

There were 125 negative statements out of the 376 in total. Hence, $33 \%$ of the statements expressed a negative opinion of homeopathic medicines. Considering that only $21 \%$ of the respondents prescribed homeopathic medicines, the level of negative responses is surprisingly low. More than half $(55 \%)$ of the negative comments are of a clear opinion that homeopathic medicines do not work. By analysing the content of the elements a common thread is found: that is, the belief that homeopathic medicines are not scientifically proven.

\section{Reasons for never prescribing homeopathic medicines}

Of the 278 respondents, $219(79 \%)$ had never prescribed homeopathic medicines. The responses were divided into 255 statements which were then categorised into nine different elements. Table 8 shows a breakdown of the various elements.

The largest single element included comment that the respondents did not prescribe mainly due to a lack of knowledge concerning homeopathic medicines. A belief that homeopathic medicines had no scientific support was also highlighted.

They also believed the products did not work. The common thread was a lack of scientific basis coupled with an ignorance or absence of knowledge concerning them.
Table 8 Respondents' comments as to why they have never prescribed homeopathic medicines

\begin{tabular}{lcc}
\hline Elements of the analysis & Number & Percent \\
\hline 1. Do not prescribe because of lack of knowledge & 142 & 56 \\
2. No scientific support & 43 & 17 \\
3. Do not believe they work & 27 & 11 \\
4. No need to prescribe such medicines & 14 & 5 \\
5. Sceptical about therapeutic value & 11 & 4 \\
6. Homeopathic medicines are too expensive & 8 & 3 \\
7. Product problems & 5 & 2 \\
8. Negative clientele perception & 1 & 0.05 \\
9. Have motivated to use but not prescribed & 4 & 1.5 \\
\hline Total & 255 & 100 \\
\hline
\end{tabular}

These responses might have been totally different if general practitioners had received some education during their medical studies. The opportunity exists for the homeopathic industry to find means of educating general practitioners about the scientific basis of their medicines either through entering medical schools if they would allow it, or providing extra curricula courses.

\section{Information sources when seeking information}

A total of 303 statements were categorised into 23 different sources where the respondents would look for information. Table 9 shows the breakdown.

There is a clear indication that unless material appears in the medical journals, homeopathy will not reach a large proportion of general practitioners. Interestingly, the Internet is ranked as the fourth largest element, having $8 \%$ of the responses, and was the second most preferred medium of information. Only three of the 303 statements name sales representatives as a source of information.

\section{Discussion}

The results will be discussed by looking at the propositions developed in this study.

P1: Private general practitioners are more strongly influenced by professional factors than marketing factors

The average mean score for the marketing factors was 1.81 and for the professional factors 2.43. Thus Proposition 1 is accepted: private general practitioners are more strongly influenced by professional factors than by marketing factors. The implications of this proposition are twofold. Firstly, if homeopathic manufacturers choose general practitioners as their target market, they will need to embark on actions that are of a more professional nature.

That is, they primarily need to devise educational programmes to include the subject of homeopathy in the educational systems of general practitioners. Influencing medical leaders to recommend their products would be another way. The publishing of studies in registered medical joumals is crucial. Overall, the emphasis must be to promote the scientific basis of homeopathy. Marketers need to ensure that scientific studies are published in the medical journals which are 
Table 9 Where respondents would look for information if they were interested?

\begin{tabular}{|c|c|c|}
\hline Analysis & Number & Percent \\
\hline 1. Registered medical joumals & 57 & 19 \\
\hline 2. Do not know & 54 & 18 \\
\hline 3. Not interested & 38 & 13 \\
\hline 4. Internet & 25 & 8 \\
\hline 5. Homeopath & 18 & 6 \\
\hline 6. Books & 16 & 5 \\
\hline 7. Medical authorities & 14 & 5 \\
\hline 8. Homeopathic journals & 11 & 4 \\
\hline 9. Interested & 10 & 3 \\
\hline 10. Consumer magazines & 9 & 3 \\
\hline 11. Pharmacists & 8 & 3 \\
\hline 12. Academy & 8 & 3 \\
\hline 13. Colleagues & 7 & 2 \\
\hline 14. Homeopathic society & 7 & 2 \\
\hline 15. Health shops & 6 & 2 \\
\hline 16. Pharmacy publications & 3 & 1 \\
\hline 17. Representatives & 3 & 1 \\
\hline 18. Media & 2 & $2 / 3$ \\
\hline 19.University library & 2 & $2 / 3$ \\
\hline 20. Experts & 2 & $2 / 3$ \\
\hline 21. Students & 1 & $1 / 3$ \\
\hline 22. Friends & 1 & $1 / 3$ \\
\hline 23. Patient & 1 & $1 / 3$ \\
\hline Total & 303 & 100 \\
\hline
\end{tabular}

read by the general practitioners. They should also engage in the politics of registration of products and their acceptance by medical authorities. The fact that their products are registered should also be publicised.

\section{P2: Sales representatives are the most influential of the} marketing factors

This proposition is dealt with by comparing the respondents' ratings of all the marketing factors. The average mean score for representatives was 1.28 , while the average mean score for all the factors including the sales representatives' score is 1.81. This is a significant difference.

The influence of sales representatives on a general practitioner to prescribe homeopathic medicines is significantly lower than the average influence of the other marketing factors. Hence this proposition must be rejected. Not only were representatives' sales presentations not the most influential of the marketing factors, they were amongst the least influential.

Of the pharmaceutical promotional tools that Pitt \& Nel (1988) researched one of the most influential was sales representatives, well ahead of conferences, advertisements and promotional material. In this study, conferences and advertising in medical joumals only, as well as the cost of the product, were rated as being more influential than representatives' sales presentations. Only sales promotional material was rated as a lower influence than representatives' sales presentations.
The explanation for these differing results could be an indication that complementary medicines' organisations were perceived as less professional than pharmaceutical companies. Thus, a sales representative from one organisation was not perceived in the same way as a representative from another organisation.

Hayes \& Hartley (1989) have reported that representatives would gain by being more professional. A good method for marketers to help increase the influence of their representatives would be for them to present scientific studies to improve the scientific credibility of their organisations.

On the other hand, Miller (1974) demonstrated that representatives were influential only at the early stage of the adoption process but not at the decision-making stage. Hence, representatives might be influential for general practitioners who are already interested in or open to homeopathic medicines, when presenting new products to them, but, in order to convince those who are not already prescribing, more would need to be done than simply a visit from a sales representative.

More importantly, homeopathic manufacturers may gain by concentrating more effort into organising conferences for the general practitioners. This marketing tool is the most influential of the marketing tools presented to the respondents. High quality conferences could be the single most important tool with which to approach the general practitioners' market. Marketing then becomes highly educational.

\section{P3: Price has the least influence of all the marketing and professional factors}

It is evident that the price factor is not the factor with the least influence. Therefore, Proposition 3 must be rejected. The cost of the product to the patient is not the least influential factor on general practitioners' decisions to prescribe homeopathic medicines. The factor with the least influence is sales promotional material.

A study in England by Stern (1997), and in the United States by O'Reilly (1991), both came to the same conclusion that price was not an influential factor. It is possible that because of the depressed South African economic environment, general practitioners are more aware of the cost of the product to the patient.

The implications of these findings are twofold. Firstly, sales promotional material should not be used as a means to convince, but to remind. Secondly, and more importantly, price does play a role in influencing general practitioners, at least in South Africa.

It is necessary for the homeopathic manufacturers to participate in policy making so that the cost of their products is covered by the medical aid societies. Most of the medical aid societies do cover some of these products (Augstburger 1998). Homeopathic manufacturers must let it be known to the general practitioners that their products are covered by the medical aid societies. Public relations, as well as direct 
contact with the general practitioners, are means of informing them of this.

P4: Prior experience with a product is the most influential factor in the professional factors

The results show that prior experience with a product is not the most influential factor. Proposition 4 is therefore rejected.

P5: The more years of practice a private general practitioner has, the less he/she is influenced by marketing factors

Analysis of Variance was conducted to see if the length of years in practice had an influence on the factors. Table 10 depicts the results.

Table $10 \mathrm{Chi}$-Square results of the length of time in practice and each factor of influence

\begin{tabular}{lcc}
\hline Factors of influence & Chi-square & P value \\
\hline Cost of the product & 1.11 & 0.89 \\
Representatives & 2.94 & 0.57 \\
Sales promotional materia! & 1.90 & 0.75 \\
Recommendations made by colleagues & 4.20 & 0.38 \\
Coverage by medical aid & 1.66 & 0.80 \\
Recommendations made by experts & 3.96 & 0.41 \\
Scholarly articles in medical journals & 0.46 & 0.98 \\
Information gained at conferences & 1.49 & 083 \\
Medical education and training & 3.52 & 0.48 \\
Advertisements in scientific journals & 4.10 & 0.40 \\
Advertisements in consumer magazines & 5.45 & 0.24 \\
Prior experience with product & 3.05 & 0.55 \\
Direct request from patients & 5.90 & 0.20 \\
\hline
\end{tabular}

Proposition 5 is rejected. There is no relation between the general practitioners' length of time in practice and the way they rate the marketing factors. This result is contrary to the results obtained by Petroshius et al. (1995).

These researchers found that, in general, physicians in practice for more than twenty years are less attentive to pharmaceutical advertising and less influenced by them. They also report that physicians with fewer than ten years of practice responded as being more attentive to pharmaceutical advertising. They explained their results by stating that older physicians received their medical training during a period when advertising of any sort was disapproved of by the medical community. Another explanation proposed is that younger physicians might be more strongly influenced by these advertisements because they are more likely to read these in an effort to keep abreast of new developments.

In any case, it is important for homeopathic manufacturers to understand that the advertising they publish may be equally looked at by the younger and older physicians.

P6: Private general practitioners with less years of practice prescribe more homeopathic medicines than their colleagues with more years of experience

The Chi-square test shows that there is no relation between the length of years in practice of the respondents and their openness to prescribe homeopathic medicines. The results show a Chi-square of 7.40 at a probability level of 0.12 . Proposition 6 is therefore rejected This result is contrary to those expected. Although it is a negative result, it can be interpreted as positive for the homeopathic manufacturers. Older practitioners are as interested in homeopathic medicines as are the younger practitioners. Hence, the effort of marketing should not concentrate on only one level of the practitioners' market, but should cover all of them.

Five propositions out of six were rejected, even though they were all based on previous research. However, these studies all concentrated on physicians' prescribing behaviour of pharmaceutical drugs, either generics or branded.

\section{Recommendations}

The homeopathic marketers' approach should differ from that of the pharmaceutical industry if they are to target the general practitioners' market.

The homeopathic marketer is confronted with a market that lacks knowledge, as well as having wrong or incomplete perceptions, about its products. In order to promote to general practitioners, the marketer must first educate them. There are many ways to achieve this. Educational marketing can take the form of traditional conferences. It can be achieved through the Intemet's CD-Roms and other types of software applications. Publishing studies in journals read by the target market could also be effective. Alternative routes would be for homeopathic marketers to try to have their therapies taught in the major educational institutions as part of the curriculum of medical degrees. Alternatively, homeopathic marketers can choose the route of a 'pull strategy' and concentrate on marketing to the end-users of their products, the consumers.

This is currently the most common route, where complementary medicine manufacturers sell their product on an over-the-counter (OTC) basis.

\section{Future research}

The first possibility would be to replicate this study in the rural areas of the country to compare the results Also this study could be directed to specialists. In view of the influence these doctors could have on general practitioners, it would be interesting to understand how homeopathic manufacturers could influence them. They could become opinion leaders. A variation of this study could be to include, in the same questionnaire, questions relating to allopathic medicines as well as homeopathic medicines. This would enable a better comprehension of the difference in the perceptions of both therapies.

The same study could also be directed to pharmacists. Such a study could provide marketers of homeopathic products or other types of products with information on how to influence the pharmacists to recommend the product to patients. These results could be compared with the behaviours of the general practitioners to gain a further understanding of the value chain. 


\section{Reforences}

Alperstein, N.M. \& Peyrot, M. 1993. Consumer awareness of prescription drug advertising, Journal of Advertising Research, 33: 50-56.

Augstburger, R. 1998. Personal communication with a member of the Homeopathic Sub-Commintee of the Complementary Medicine Committee, held in the member's office, March 24.

Avorn, J., Chen, M. \& Hartley, R. 1982. Scientific versus commercial sources of influence on the prescribing behaviour of physicians, The American Journal of Medicine, 73: 4-8

Belio, D.C. \& Lothia, R. 1993. Improving trade show effectiveness by analysing attendees, Industrial Marketing Management, 22: 311-318.

Bendixen, M.T. \& Sandler, M. 1995. Converting verbal scales to interval scales using correspondence analysis, Management Dynamics: Contemporary Research, 4: 31-49.

Check, W.A. 1983. Prescription drug advertising's inherent hazards, Advertising Age, September 26.

Corcoran, F.M. \& Sullivan, C. 1996 . Enhancing ROI through exhibiting, Medical Marketing \& Media, 31: 40-44.

Eisenberg, M.D., Kessler, R.C., Foster, C., Norlock, F.E., Calkins, D.R. \& Delbanco, T.L. 1993. Unconventional medicine in the United States, The New England Journal of Medicine, January 28 246-252.

Friedman, M.I. 1991. Factors influencing general practitioners, in their choice of prescription drugs. Unpublished Research Report. Johannesburg: University of the Witwatersrand.

Gemigneni, J. 1997. The inside story on OTCs, Business \& Health, January: 41.

Gordon, S. 1992. Pharmaceuticals - a marketer's nightmare, Marketing Mix, November: 16-25.

Hayes, H.M. \& Hartley, W.S. 1989. How buyers view industrial salespeople, Industrial Marketing Management, 18: 73-80.
Johnson, J.W. \& Lewin, J.E. 1996. Organisational buying behaviour toward an integrative framework, Journal of Business Research, 35: $1-15$.

Lagace, R.R., Dahlstrom, R. \& Gassenheimer, J.B. 1991. The rele. vance of ethical salesperson behaviour on relationship quality: the pharmaceutical industry, Journal of Personal Selling \& Sales Management, XI: 39-47.

Lin, B. \& Dwyer, D.S. 1995. New product development in the information age: pharmaceutical industry, Journal of Business \& Industrial Marketing, 10:6-17.

Miller, R.R. 1974. Prescribing habits of physicians, Drug Intelligence Clinical Pharmacy, 8: 85

O'Reilly, B. 1991. Drugmakers, Fortune, July 29: 108-118.

Petroshius, S.M., Titus, P.A. \& Hatch, K.J. 1995. Physician attitudes toward pharmaceutical drug advertising, Journal of Advertising Research, November/December: 41-51.

Pitt, L. and Nel, N. 1988. Pharmaceutical promotional tools - their relative importance, European Journal of Marketing, 22: 6-14.

Smith, P. 1996. The treatment of allergy from a homeopathic perspective, Current Allergy and Clinical Immunology, September 9: 23-25.

Stern, P. 1994. Patterns of pharmaceutical prescribing. Unpublished Ph.D. thesis, London: London Business School.

Stern, P. 1997. Long run loyalty an exploratory study, Marketing and Research Today, May: 70-78.

Stolley, P.D. \& Lasagna, L. 1969. Prescribing patterns of physicians, Journal of Chronic Disease, 22: 395-405.

Walt, L. 1989. Factors which influence the medical specialist's decisions to prescribe scheduled pharmaceutical products. Unpublished MBA Research Report. Cape Town: University of Cape Town.

Walton, H. 1980. Ad recognition and prescribing by physicians, Journal of Advertising Research, 20: 39-48. 